ARTICLE

https://doi.org/10.1038/s41467-019-10240-x

\title{
Ultra-selective ligand-driven separation of strategic actinides
}

\author{
Gauthier J.-P. Deblonde (1D ${ }^{1}$, Abel Ricano ${ }^{1} \&$ Rebecca J. Abergel ${ }^{1,2}$
}

Metal ion separations are critical to numerous fields, including nuclear medicine, waste recycling, space exploration, and fundamental research. Nonetheless, operational conditions and performance are limited, imposing compromises between recovery, purity, and cost. Siderophore-inspired ligands show unprecedented charge-based selectivity and compatibility with harsh industry conditions, affording excellent separation efficiency, robustness and process control. Here, we successfully demonstrate a general separation strategy on three distinct systems, for Ac, Pu, and Bk purification. Separation factors (SF) obtained with model compound 3,4,3-LI(1,2-HOPO) are orders of magnitude higher than with any other ligand currently employed: $10^{6}$ between $A c$ and relevant metal impurities, and over $10^{8}$ for redoxfree $\mathrm{Pu}$ purification against uranyl ions and trivalent actinides or fission products. Finally, a one-step separation method (SF $>3 \times 10^{6}$ and radiopurity $>99.999 \%$ ) enables the isolation of $\mathrm{Bk}$ from adjacent actinides and fission products. The proposed approach offers a paradigm change for the production of strategic elements.

\footnotetext{
${ }^{1}$ Chemical Sciences Division, Lawrence Berkeley National Laboratory, Berkeley, CA 94720, USA. ${ }^{2}$ Department of Nuclear Engineering, University of California, Berkeley, CA 94720, USA. Correspondence and requests for materials should be addressed to R.J.A. (email: abergel@berkeley.edu)
} 
sotope production has been the cornerstone of many research fields and applications throughout the last century ${ }^{1}$ and relies largely on separation science. Contemporary examples illustrating the primary importance of separations include radionuclide purification for use in radiopharmaceuticals ${ }^{2}$ or in radioactive thermoelectric generators that are vital to space exploration ${ }^{3}$. The development of efficient separation methods is also critical for forensics analysis, recycling of ageing weapon materials, fabrication of nuclear fuels ${ }^{4}$, production of radiotracers for research ${ }^{5}$, as well as manufacturing of high-purity actinide targets for the discovery of new elements ${ }^{6}$. Regardless of the application, product purity must be as high as possible, which requires highly efficient and cost-effective separation methods. Radionuclide production through either target irradiation $\left({ }^{225} \mathrm{Ac}\right.$, ${ }^{177} \mathrm{Lu},{ }^{90 / 86} \mathrm{Y},{ }^{89} \mathrm{Zr},{ }^{47 / 44} \mathrm{Sc},{ }^{238} \mathrm{Pu},{ }^{248} \mathrm{Cm},{ }^{249} \mathrm{Bk},{ }^{249 / 252} \mathrm{Cf}$, etc.) or milking from long-lived sources $\left({ }^{227} \mathrm{Ac} \rightarrow{ }^{227} \mathrm{Th} \rightarrow{ }^{223} \mathrm{Ra}\right.$, ${ }^{241} \mathrm{Pu} \rightarrow{ }^{241} \mathrm{Am},{ }^{233} \mathrm{U} \rightarrow{ }^{229} \mathrm{Th} \rightarrow{ }^{225} \mathrm{Ra} \rightarrow{ }^{225} \mathrm{Ac},{ }^{232} \mathrm{Th} \rightarrow{ }^{212} \mathrm{~Pb}$, etc.) involves the handling of mixtures of metal ions where major impurities are often neighboring elements in the periodic table. In most cases, the ratio between the valuable element and impurities is extremely high (a few $\mu$ g diluted in multi-g targets), rendering purification very challenging, albeit critical for the availability of the coveted isotope.

Recent reports have highlighted the creative use of solid matrices, such as crystalline selenites ${ }^{7}$ or borates ${ }^{8}$, to quantitatively separate f-elements. However, most at-scale chemical purifications rely on chromatographic separations or liquid-liquid extraction methods or both, depending on the process scale and the desired specifications. These bi-phasic techniques are based on intrinsic interactions between metal ions and organic molecules dissolved in an organic diluent (liquid-liquid extraction) or grafted onto a solid matrix (chromatography). Ideally, these organic molecules (hereafter referred to as extractants) are amenable to transfer ions of interest from one phase to another in a selective manner relative to impurities. Extractant performance is typically not predictable and not always transposable from one separation system to another. In fact, predicting the efficiency and metal selectivity of a given process formulation (aqueous phase, diluent, and extractant) is a scientific challenge with numerous correlated variables 9,10 , such as metal speciation in the aqueous phase, metal-extractant compound speciation in the organic phase, free extractant speciation, influence of the diluent, loading capacity of the organic phase, etc. Most extractants currently used in hydrometallurgy can potentially co-extract multiple elements depending on chemical conditions (acidity, extractant concentration, phase ratio etc.) ${ }^{11-13}$. Separation selectivity is only achieved by finely tuning those chemical conditions and operational conditions for these processes are generally highly constrained, with many required steps to reach desired purities.

To overcome these challenges, a class of hydroxypyridinone (HOPO) chelators was investigated for its high metal-binding selectivity and applicability to separation needs. These molecules exhibit a unique combination of properties long sought in separation science: (i) water-solubility, (ii) structures consisting of solely $\mathrm{H}, \mathrm{C}, \mathrm{N}$, and $\mathrm{O}$ atoms, (iii) ability to control metal oxidation states without additional redox-active species, (iv) extremely high charge-based selectivity, and (v) high metalligand complex stability even in strong acid (up to $10 \mathrm{M} \mathrm{H}^{+}$). Using the model octadentate HOPO chelator, 3,4,3-LI(1,2HOPO) (hereafter referred to as $343 \mathrm{HOPO}$ ), and taking advantage of these unprecedented characteristics, highly efficient and robust chemical separation processes were developed for three strategic examples: the purification of ${ }^{225} \mathrm{Ac}, \mathrm{Pu}$-isotopes, and ${ }^{249} \mathrm{Bk}$.

\section{Results and Discussion}

Choice of aqueous chelator as hold-back reagent. Numerous drug development studies ${ }^{14-16}$ have focused on synthetic siderophore-inspired compounds because of their ability to form stable, and sometimes luminescent, complexes with metal ions of interest for medical imaging, radionuclide decontamination, and cancer treatments. While this class of ligands, encompassing HOPO and catecholamide (CAM) derivatives, has been known for decades, it had never been studied in details for separation applications. In fact, a few exceptions aside, most of these chelators have only been studied with a single cation, such as $\mathrm{Gd}^{3+}$, $\mathrm{Th}^{4+}$, or $\mathrm{Pu}^{4+}$, impairing broader evaluation of their metal-metal selectivity. The chemistry of some HOPO ligands was recently extended across the periodic table, highlighting their outstanding selectivity, and large superiority over polyaminocarboxylate chelators (IDA, EDTA, DTPA, etc.), typically encountered in separations (Fig. 1). A comparison of metal complex formation constants for the octadentate $343 \mathrm{HOPO}$ shows striking differences between tetravalent species and corresponding divalent or trivalent ones. The observed selectivity seems mainly chargebased and only slightly dependent on the ionic radius of the cations (Supplementary Fig. 1), although some selectivity is noted across the trivalent lanthanide and actinide series. $343 \mathrm{HOPO}$ outperforms any known chelator in terms of charge-specific selectivity and, in particular, for the binding of tetravalent ions. As such, the $\mathrm{Ce}^{4+} / \mathrm{Ce}^{3+}$ selectivity of $343 \mathrm{HOPO}$ is about 15 orders of magnitude higher than what could be expected from a carboxylate ligand. Extreme selectivity is also observed even for ions of similar size, such as in the $\mathrm{Th}^{4+} / \mathrm{Am}^{3+}, \mathrm{Th}^{4+} / \mathrm{Gd}^{3+}, \mathrm{Ce}^{4}$ $+/ \mathrm{Lu}^{3+}$, or $\mathrm{Th}^{4+} / \mathrm{Cd}^{2+}$ pairs (Fig. 1 and Supplementary Fig. 2). As shown in Fig. 1, a handful of other molecules from the same family (octadentate 3,4,3-LI-CAM, Bis-TREN-Me-3,2-HOPO, and TAM-macrocycle; tetradentate 5LI-Me-3,2-HOPO, 5LIOMe-3,2-HOPO; and bidentate PR-Me-3,2-HOPO) ${ }^{17-20}$ exhibit known solution thermodynamic properties that match those of $343 \mathrm{HOPO}$ but none of the chelators typically used for separation methods is nearly as selective. Many additional HOPO and CAM ligands have been designed ${ }^{15}$ and previously reported octadentate 1,2-HOPO ${ }^{21}$, mixed 3,4,3-LI(1,2-HOPO/Me-3,2-HOPO $)^{22}$, and $\mathrm{DFO} / 1,2-\mathrm{HOPO}^{23}$ structures would certainly make excellent candidates for charge-based selectivity; however, their chelation properties have so far only been investigated with either $\mathrm{Eu}^{3+}$, $\mathrm{Zr}^{4+}$, or $\mathrm{Pu}^{4+}$. Due to its current $\mathrm{kg}$-scale availability and established solution thermodynamics, $343 \mathrm{HOPO}$ was used here as a model case. It was not initially designed for separation applications and its performance should not be considered as the upper limit for a separation strategy that could be extended to an entire molecular family.

The selectivity of $343 \mathrm{HOPO}$ for tetravalent ions is so high that it is expected to form complexes even under very acidic conditions (experimentally observed ${ }^{24}$ in $3 \mathrm{M} \mathrm{HCl}$ for $\mathrm{Sn}^{4+}$ ), whereas it should release trivalent ${ }^{25}$ and divalent ${ }^{24,26}$ ions completely below pH 2 (Fig. 1). To our knowledge, no other reported class of ligands exhibits such behavior. The clear metal discrimination afforded by $343 \mathrm{HOPO}$ (bound $\mathrm{M}^{4+}$ versus free $\mathrm{M}^{3+/ 2+/ 1+}$ ) can therefore be leveraged as a chemical switch to isolate charged ions, a needed tool when separating $\mathrm{Ac}^{3+} / \mathrm{Th}^{4+}$ or $\mathrm{Pu}^{4+} / \mathrm{Am}^{3+}$ mixtures. If such an ultra-selective complexant is present in the aqueous phase, overall process selectivity is expected to be decoupled from extractant selectivity, since a system containing $343 \mathrm{HOPO}$ in the aqueous phase and a completely non-selective extractant in the organic phase will still result in highly efficient separation. Such ligand-driven performance enables more flexible solvent formulation and operational process conditions. It will also spare the cumbersome 

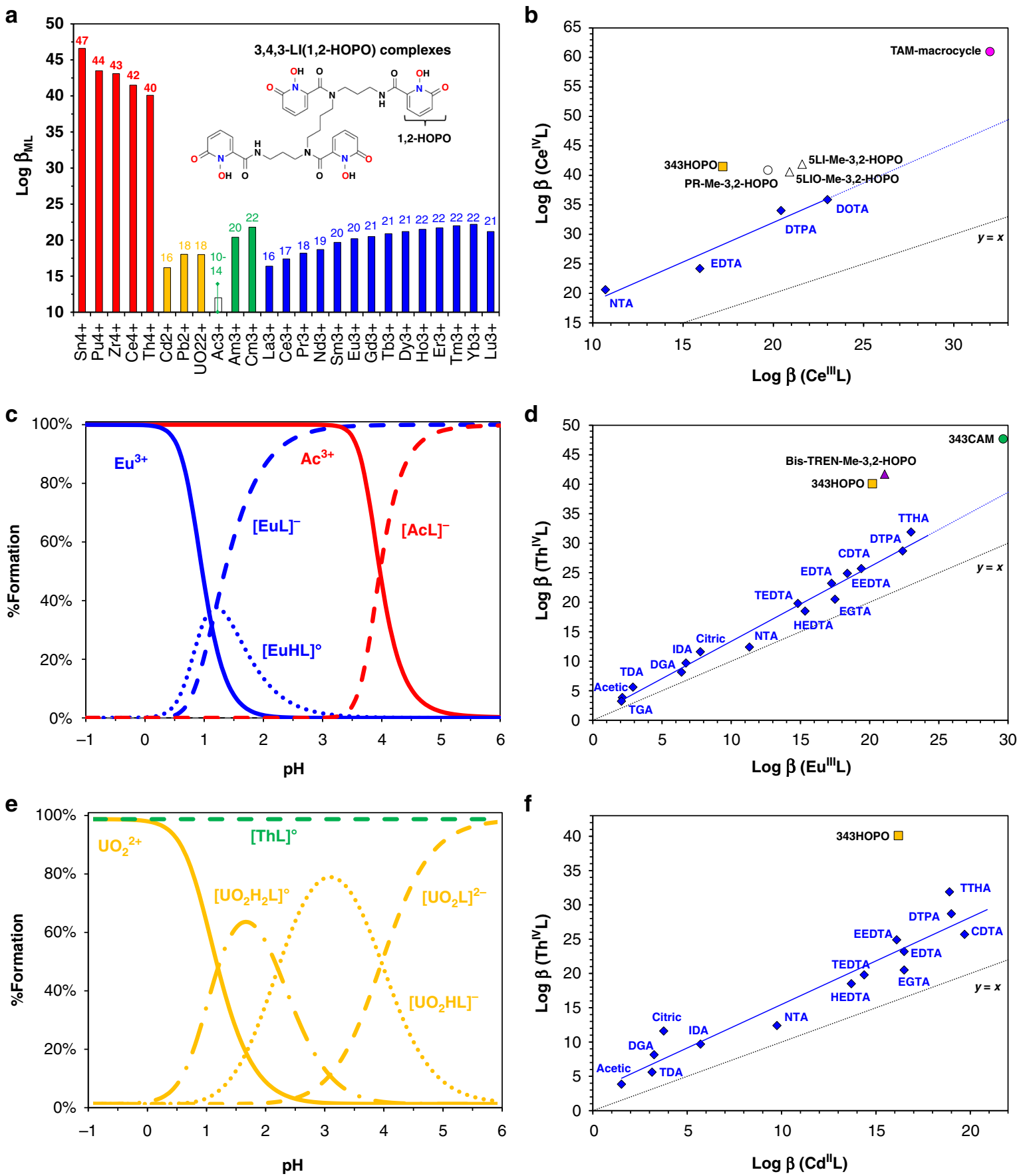

Fig. 1 Relative thermodynamic stabilities of metal-ligand complexes discussed in this work. a Stability constants $\left(\log \beta_{\mathrm{ML}}\right)^{24,25,46,48-50}$ of $343 \mathrm{HOPO}$ complexes with tetravalent cations (red), divalent ions (yellow), trivalent actinides (green), and trivalent lanthanides (blue). The value plotted for $\mathrm{Ac}^{3+}$ is an estimate based on its ionic radius. Selectivity comparisons for $\mathrm{Ce}^{4+} / \mathrm{Ce}^{3+}(\mathbf{b}), \mathrm{Th}^{4+} / \mathrm{Eu}^{3+}(\mathbf{d})$, and $\mathrm{Th}^{4+} / \mathrm{Cd}^{2+}(\mathbf{f})$, with $\mathrm{HOPO}$ and CAM ligands and classical chelators used in separations. For tetradentate ligands 5-LIO-Me-3,2-HOPO and 5-LI-Me-3,2-HOPO, the $\beta_{\mathrm{ML} 2}$ value is used. For bidentate PR-Me$3,2-\mathrm{HOPO}$, the $\beta_{\mathrm{ML} 4}$ value is used. The line $\mathrm{y}=\mathrm{x}$ corresponds to no selectivity. Additional selectivity comparisons are given in Supplementary Fig. 2. Full ligand names and structures are given in Supplementary Table 1. Metal speciation diagrams for $343 \mathrm{HOPO}$ solutions containing $\mathrm{Ac}^{3+}$ or Eu ${ }^{3+}$ (c) and $\mathrm{UO}_{2}{ }^{2+}$ or $\mathrm{Th}^{4+}(\mathbf{e})$. [Chelator]/[Metal] $=1 \mathrm{~mol} / \mathrm{mol}$. L $=$ Ligand. Solid lines: free metal. Dotted lines: $343 \mathrm{HOPO}$ complexes

development of new extractants and can be applied to a variety of $\mathrm{M}^{\mathrm{x}+} / \mathrm{M}^{\mathrm{y}+}$ pairs, as demonstrated below.

Actinium purification. While there is great interest in using ${ }^{225} \mathrm{Ac}$ for targeted alpha therapy ${ }^{27,28}$, the development of ${ }^{225} \mathrm{Ac}-$ based pharmaceuticals is still hindered by low isotope availability relative to potential market needs ${ }^{1}$. Furthermore, Ac chemistry is largely unexplored since (i) $\mathrm{Ac}^{3+}$ being the biggest trivalent ion of the periodic table ${ }^{28,29}$, there is no adequate surrogate to study its chemistry, and (ii) its highly-radioactive longest-lived isotope $\left({ }^{227} \mathrm{Ac}, t_{1 / 2}=21.8\right.$ year) is available in only $\mu \mathrm{g}$ amounts. Both ${ }^{227} \mathrm{Ac}$ decay and ${ }^{225} \mathrm{Ac}$ production yield mixtures of $\mathrm{Ac}^{3+}$, $\mathrm{Th}^{4+}, \mathrm{Ra}^{2+}$, and trivalent lanthanides. The ratio between unwanted elements and Ac is typically very high and purification options are limited ${ }^{30} .343 \mathrm{HOPO}$ exhibits very low affinity toward 
$\mathrm{Ac}^{3+}$ compared with other trivalent ions and has extremely high affinity for tetravalent ions, providing a straightforward tool to selectively isolate Ac. Figure 2 shows the $\mathrm{Ac}^{3+}$ and $\mathrm{Pu}^{4+}$ extraction yields by HDEHP (extractant widely used in hydrometallurgy, also known as D2EHPA) $)^{31,32}$ in the presence of $343 \mathrm{HOPO}$ at different $\mathrm{pH}$ values. Full $\mathrm{Ac}^{3+}$ extraction in the organic layer was achieved, while scavenging $\mathrm{Pu}^{4+}$ (a surrogate for $\mathrm{Th}^{4+}$ ) in the aqueous layer. Similar experiments in the presence of reference aqueous chelator DTPA, also used in the socalled TALSPEAK process $^{31}$, showed partial extraction of both isotopes and no practical separation or recovery. After only a single step and despite a large initial $\mathrm{Pu} / \mathrm{Ac}$ ratio $(\sim 10,000 \mathrm{~mol} /$ $\mathrm{mol}), \mathrm{SF}_{\mathrm{Ac} / \mathrm{Pu}}$ values reached at least $1,000,000$ in the presence of $343 \mathrm{HOPO}$, combined with recovery yields of up to $99.70 \%$ for $\mathrm{Ac}$ in the organic phase and higher than $99.97 \%$ for $\mathrm{Pu}$ in the aqueous phase. In comparison, DTPA $\mathrm{SF}_{\mathrm{Ac} / \mathrm{Pu}}$ values were between 1 and 100, the typical selectivity range observed in hydrometallurgical processes, with less than 50\% Ac recovery. Separation of Ac from trivalent impurities was also investigated. Figure 3 displays $\mathrm{Ac}^{3+}, \mathrm{Am}^{3+}$, and $\mathrm{Gd}^{3+}$ extraction profiles in
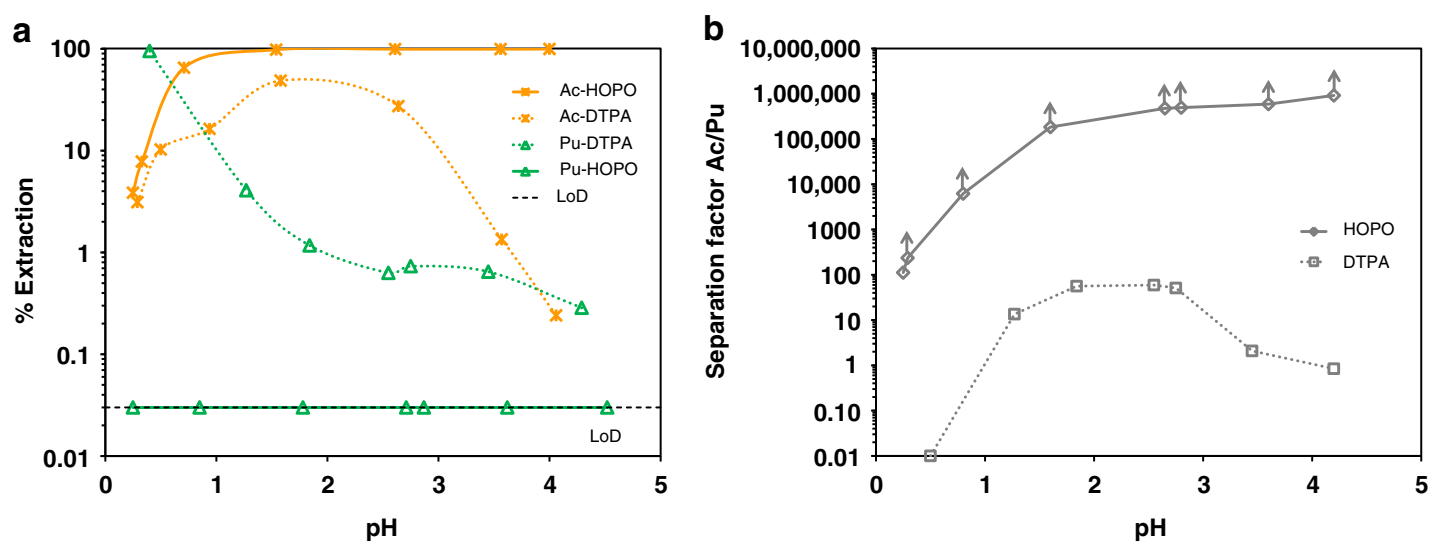

Fig. 2 Separation of Ac from Pu. a Extraction yield of $\mathrm{Ac}^{3+}$ (stars) and $\mathrm{Pu}^{4+}$ (triangles) by $0.5 \mathrm{M}$ HDEHP as a function of $\mathrm{pH}$, in the presence of DTPA (dotted lines) or $343 \mathrm{HOPO}$ (solid lines). A logarithmic scale is used due to the low extraction yields of $\mathrm{Pu}^{4+}$. b Corresponding separation factors. Aqueous phase: $40 \mathrm{mM}$ of chelator in sodium lactate/sodium nitrate buffer $(I=2 \mathrm{M}) \cdot V_{\mathrm{org}} / V_{\mathrm{aq}}=1 . T=25^{\circ} \mathrm{C}$. LoD $=$ Limit of detection. Data points with arrows are lower limits
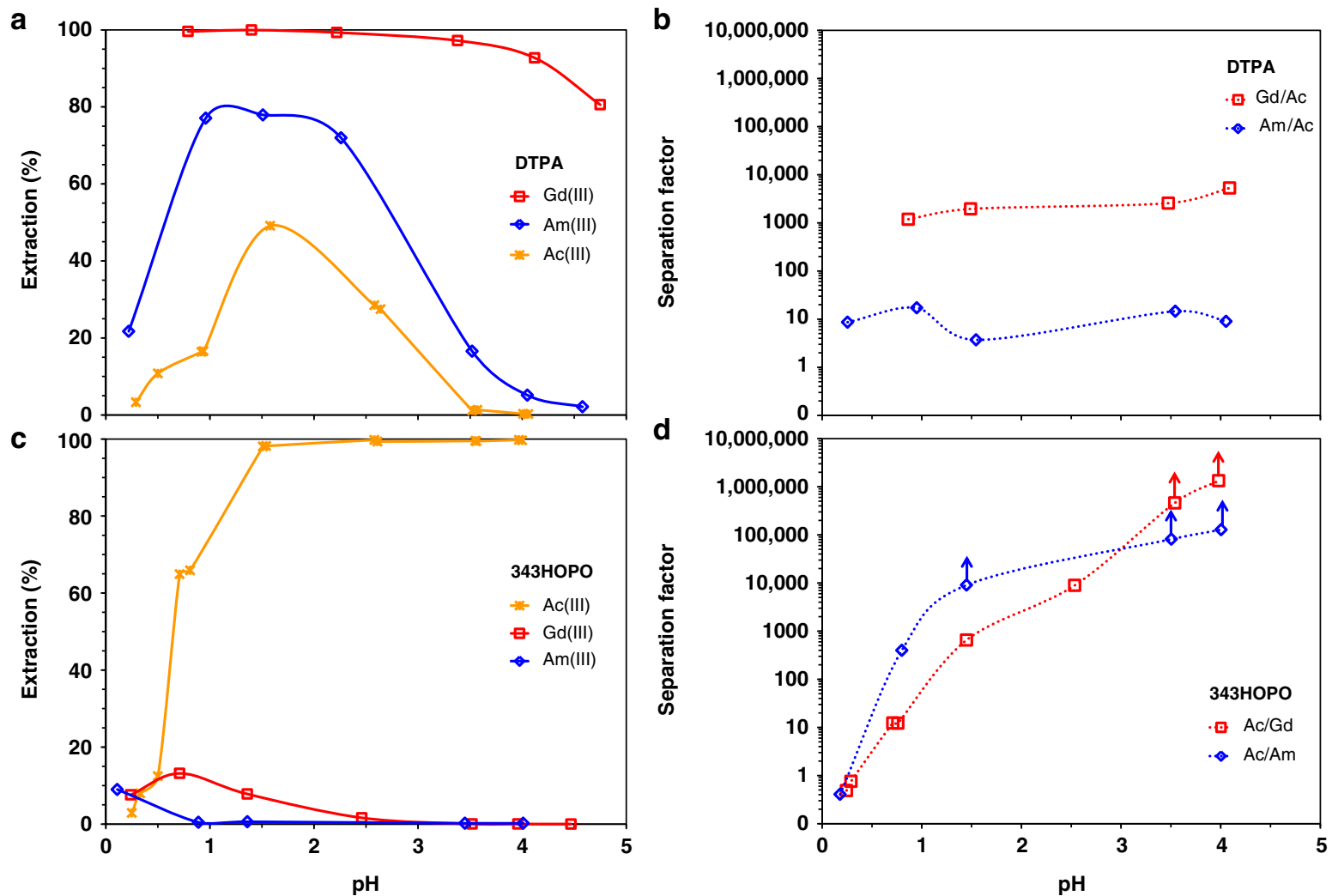

Fig. 3 Separation of Ac from Gd and Am. Extraction yield of trivalent Ac (stars), Gd (squares), and Am (circles) by $0.5 \mathrm{M} \mathrm{HDEHP}$ as a function of pH, in the presence of DTPA (a) or $343 \mathrm{HOPO}(\mathbf{c})$. A logarithmic scale is used due to the low extraction yields of $\mathrm{Pu}^{4+}$. The corresponding separation factors in the presence of DTPA or $343 \mathrm{HOPO}$ are given in $\mathbf{b}$ and $\mathbf{d}$, respectively. Aqueous phase: $40 \mathrm{mM}$ of chelator in sodium lactate/sodium nitrate buffer ( $I=2 \mathrm{M}$ ). $V_{\text {org }} / V_{\text {aq }}=1$, one contact. $T=25^{\circ} \mathrm{C}$. Data points with arrows are lower limits 
both $\mathrm{HDEHP} / 343 \mathrm{HOPO}-\mathrm{HNO}_{3}$ and $\mathrm{HDEHP} / \mathrm{DTPA}-\mathrm{HNO}_{3}$ systems. Significant discrimination was observed for $\mathrm{Ac}^{3+}$ against $\mathrm{Am}^{3+}$ and $\mathrm{Gd}^{3+}$, with $\mathrm{SF}_{\mathrm{Ac} / \mathrm{Am}}$ and $\mathrm{SF}_{\mathrm{Ac} / \mathrm{Gd}}$ reaching 130,000 and $1,300,000$, respectively. In the DTPA case, $\mathrm{SF}_{\mathrm{Am} / \mathrm{Ac}}$ and $\mathrm{SF}_{\mathrm{Gd} / \mathrm{Ac}}$ values were below 10 and 5300, respectively, and Ac recovery was low. A process flowsheet for ${ }^{225} \mathrm{Ac}$ purification using the 343 HOPO-HDEHP combination is proposed in Supplementary Fig. 3.

Plutonium purification. Since the 1940 's, worldwide Pu inventory has evolved from almost 0 to $2,500,000 \mathrm{~kg}$ due to anthropogenic activities $^{33,34}$, and is estimated to increase by $70,000 \mathrm{~kg} / \mathrm{year}^{35}$ based on civilian nuclear power generation forecasts. Pu materials must be properly safeguarded throughout their lifespan, which necessitates advanced nuclear forensic controls and reprocessing activities. In this context, isolation of $\mathrm{Pu}$ from minor actinide and fission product impurities is essential. The standard PUREX (Plutonium Uranium Redox EXtraction) liquid-liquid extraction process $^{36}$ allows recovering and separating $\mathrm{Pu}$ and $\mathrm{U}$ from minor actinides and fission products. PUREX operates in concentrated $\mathrm{HNO}_{3}$ media and includes two critical steps: (i) $\mathrm{UO}_{2}{ }^{2+}$ and $\mathrm{Pu}^{4+}$ co-extraction into the organic phase (30\% TBP in diluent) while leaving trivalent ions in the aqueous phase, and (ii) reductive back-extraction of $\mathrm{Pu}$ as $\mathrm{Pu}^{3+}$ while leaving $\mathrm{UO}_{2}{ }^{2+}$ in the organic phase. The latter is indispensable for $\mathrm{U} / \mathrm{Pu}$ separation because of TBP's lack of selectivity between tetravalent and actinyl species. While reduction of $\mathrm{Pu}^{4+}$ to $\mathrm{Pu}^{3+}$ is achieved by addition of strong reducing agents into the liquid-liquid extraction batteries ${ }^{37}$, $\mathrm{Pu}^{3+}$ is inherently unstable, and this redox component creates constraints in the reactive TBP-nitric medium (reduction of $\mathrm{HNO}_{3}$ to $\mathrm{HNO}_{2}$ and formation of potentially explosive compounds such as $\mathrm{HN}_{3}$ ).

A simple but effective modification of PUREX was investigated for non-reductive separation of $\mathrm{Pu}$ and $\mathrm{U}$ (Supplementary Fig. 4). Figure 4 shows that $\mathrm{Pu}^{4+}$ and $\mathrm{UO}_{2}{ }^{2+}$ extraction behaviors under typical PUREX conditions are expectedly very similar, with quantitative extraction of both elements and $\mathrm{SF}_{\mathrm{U} / \mathrm{Pu}}$ values below 3. After co-extraction of $\mathrm{U}$ and $\mathrm{Pu}$ by TBP, the unprecedented chelation properties of $343 \mathrm{HOPO}$ at high acidity and its chargebased selectivity can be leveraged to selectively strip $\mathrm{Pu}^{4+}$ from the organic phase. Efficient $\mathrm{U} / \mathrm{Pu}$ separation was observed in the presence of $343 \mathrm{HOPO}$ (Fig. 4) by selective chelation of $\mathrm{Pu}^{4+}$, without significant interactions with $\mathrm{UO}_{2}{ }^{2+}$ over a broad range of acidity (up to $8 \mathrm{M} \mathrm{HNO}_{3}$ ) and $\mathrm{SF}_{\mathrm{U} / \mathrm{Pu}}$ values as high as 5800 . The use of $343 \mathrm{HOPO}$-type chelators could afford straightforward and efficient separation methods for the purification of $\mathrm{U}$ and $\mathrm{Pu}$, and so, without using any redox-active chemical or non-volatile contaminant. This method also leads to very flexible process control, as demonstrated by the broad acidity range under which $343 \mathrm{HOPO}$ selectively scavenges $\mathrm{Pu}^{4+}$.

Another route, using TODGA as extractant, was explored for the purification of $\mathrm{Pu}$ not only from divalent ions but also from trivalent metals. TODGA is from the diglycolamide family used for resins separations ${ }^{38,39}$, and is currently investigated for nextgeneration nuclear waste treatment processes, such as EUROGANEX $^{11,40,41}$. TODGA is effective at extracting trivalent lanthanides and actinides from concentrated nitric media but its selectivity toward other ions, such as $\mathrm{Pu}^{4+}$, is very low. Very high yields were observed for the extraction of $\mathrm{Gd}^{3+}, \mathrm{Lu}^{3+}, \mathrm{UO}_{2}{ }^{2}$ ,$+ \mathrm{Pu}^{4+}$, and $\mathrm{Cf}^{3+}$ from $\mathrm{HNO}_{3}\left(>99.5 \%\right.$ if $\left.\mathrm{HNO}_{3}>1 \mathrm{M}\right)$, emphasizing the lack of potential for practical separation (Fig. 4). In the presence of $343 \mathrm{HOPO}, \mathrm{Pu}^{4+}$ is selectively held-back in the aqueous phase whereas the extraction behaviors of trivalent actinides, lanthanides, and uranyl are not impacted, offering a direct avenue for Pu recovery. SF values between the trivalent ions and $\mathrm{Pu}^{4+}$ are above $450,000,000$ (LoD reached) whereas $\mathrm{SF}_{\mathrm{U} / \mathrm{Pu}}$ values are around $50,000 . \mathrm{SF}_{\mathrm{U} / \mathrm{Pu}}$ values are limited by the relatively low distribution factors of uranyl $\left(\mathrm{D}_{\mathrm{U}}<30\right)$ when using TODGA, as observed here and elsewhere ${ }^{11}$. Combining the high affinity of TODGA for trivalent lanthanides and actinides with the high affinity of TBP for uranyl and the selectivity of $343 \mathrm{HOPO}$ for $\mathrm{Pu}$, a redox-free process was devised for the flashrecovery and purification of $\mathrm{Pu}$ from materials containing $\mathrm{Pu}$, uranyl, minor actinides, and fission products (Supplementary Fig. 5).

Berkelium purification. Bk and Cf are of particular interest due to their use as targets for the production of super-heavy elements, such as elements 117 (tennessine, named after a ${ }^{249} \mathrm{Bk}$ target manufactured at Oak Ridge National Laboratory - ORNL, Tennessee ${ }^{42}$ and 118 (oganesson, produced from ${ }^{249} \mathrm{Cf}$ ) ${ }^{43} \cdot{ }^{252} \mathrm{Cf}$ is also a strategic isotope for oil and gas exploration as well as quality control of nuclear reactors ${ }^{1}$. Bk and $\mathrm{Cf}$ are produced via prolonged neutron irradiation of $\mathrm{Am} / \mathrm{Cm}$ targets, yielding mixtures of actinides from Am to Fm and some fission products ${ }^{5}$. These transplutonium elements have traditionally displayed very similar chemistries as they exhibit the +III oxidation state in solution and have almost identical ionic radii ${ }^{44}$. To separate $\mathrm{Cf}^{3+}$ from $\mathrm{Bk}^{3+}, \mathrm{Bk}^{3+}$ can eventually be oxidized to $\mathrm{Bk}^{4+}$ under harsh conditions (heating combined with excess $\mathrm{NaBrO}_{3}$ in $8 \mathrm{M} \mathrm{HNO}_{3}$ ) but it is unstable, which adds another level of complications to the eventual separation scheme. Campaigns conducted at ORNL for the purification of $\mathrm{mg}$ amounts of ${ }^{249} \mathrm{Bk}$ take several months $s^{5,45}$ and result in relatively limited purification factors. The Bk isolation process ${ }^{5}$ comprises about 25 steps, with a purification factor for the entire procedure (product of SF values from all steps) of $\sim 10^{7}$.

$343 \mathrm{HOPO}$ was recently shown ${ }^{46}$ to oxidize $\mathrm{Bk}^{3+}$ and stabilize $\mathrm{Bk}^{4+}$ in aqueous solution without addition of any redox-active species; a direct consequence of the ligand's thermodynamic preference for tetravalent cations (vide supra). The separation strategy detailed above can therefore be applied to the isolation of $\mathrm{Bk}$ from all trivalent ions. Preliminary tests with extractant HDEHP at high acidity $\left(0.1-6 \mathrm{M} \mathrm{HNO}_{3}\right)$ show a drastic influence of $343 \mathrm{HOPO}$ on the Bk extraction by HDEHP (Supplementary Fig. 6). Comparisons with $\mathrm{Pu}^{4+}, \mathrm{Gd}^{3+}$, and $\mathrm{Cf}^{3+}$ confirm that $\mathrm{Bk}$ exists as $\mathrm{Bk}^{3+}$ in nitric media without chelator but forms a $\mathrm{Bk}^{4+}$ complex with $343 \mathrm{HOPO}$ even under very acidic conditions (Supplementary Fig. 7). Thus, isolation of Bk from its trivalent neighbors and lanthanides was studied in the HDEHP$\mathrm{HNO}_{3}-343 \mathrm{HOPO}$ system (Fig. 5). After a single step at room temperature, high extraction yields were observed for all tested trivalent ions, whereas $\mathrm{Bk}$ was selectively sequestered in the aqueous phase. $\mathrm{SF}_{\mathrm{Bk} / \mathrm{Lu}}$ values as high as 320,000 were obtained, and SF values between 3000 and 10,000 were reached between Bk and adjacent actinides $\mathrm{Am}^{3+}, \mathrm{Cf}^{3+}$, and $\mathrm{Es}^{3+}$. Similar tests in the presence of NTA, EDTA, CDTA, and DTPA showed no separation at all between Bk and Cf, (similar to what is observed without chelator) since this type of ligands is not strong enough to bind metal ions under acidic conditions and is not selective enough to oxidize $\mathrm{Bk}^{3+}$ to $\mathrm{Bk}^{4+}$. Importantly (Fig. 5 and Supplementary Fig. 8), the behavior of Bk in the presence of $343 \mathrm{HOPO}$ is completely decoupled from classic extraction parameters (extractant concentration, phase ratio), resulting in stable separation performance and robustness over a wide range of conditions. Given the system SF values, two consecutive steps would yield purification factors similar or higher than the current state-of-the-art process 5 .

$\mathrm{Bk}$ purification using TODGA as extractant was also investigated. TODGA is more relevant than HDEHP for the 

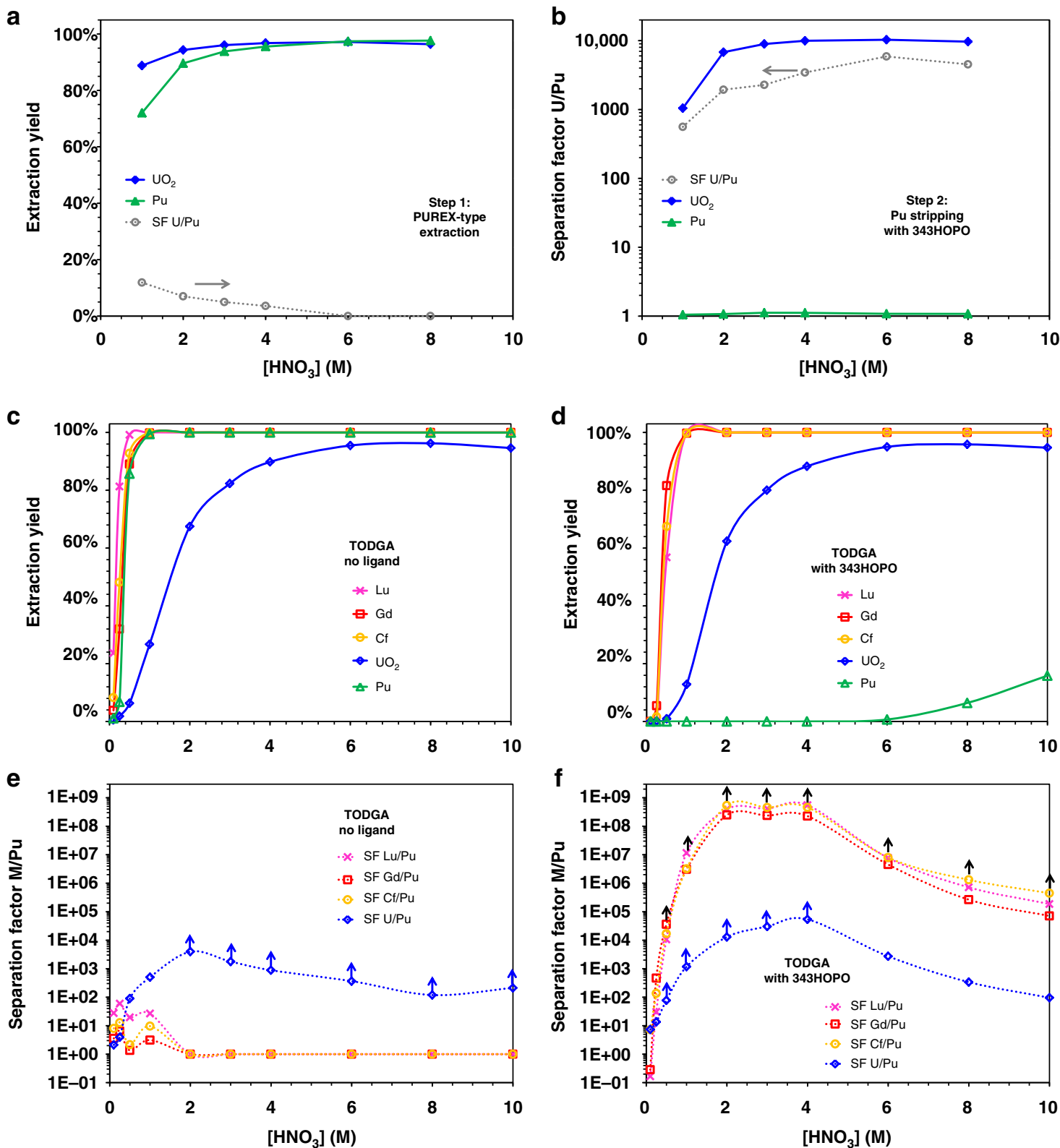

Fig. 4 Separation of Pu from U, Gd, Lu, and Cf. Extraction of Pu4+ (triangles) and $\mathrm{UO}_{2}{ }^{2+}$ (diamonds) under typical PUREX conditions (a) and backextraction in the presence of $1 \mathrm{mM} 343 \mathrm{HOPO}$ (b). Dotted lines: separation factor U/Pu. Organic phase: $30 \%$ TBP in kerosene. c and $\mathbf{d}$ show the extraction yields of $\mathrm{Gd}^{3+}$ (squares), $\mathrm{Lu}^{3+}$ (crosses), $\mathrm{Cf}^{3+}$ (circles), $\mathrm{UO}_{2}{ }^{2+}$, and $\mathrm{Pu}^{4+}$ by TODGA in the absence or presence of $1 \mathrm{mM} 343 \mathrm{HOPO}$, respectively. Corresponding separation factors are given in e and f. Organic phase: $0.1 \mathrm{M} \mathrm{TODGA}$ in kerosene. Aqueous solvent: $\mathrm{HNO}_{3} . T=25^{\circ} \mathrm{C}$. O/A $=1$, one contact. Points with arrows are lower limits

production of heavy actinides since it is effective at high acidity and is therefore compatible with the post-irradiation metallic target dissolution step. The extraction behavior of $\mathrm{Bk}$ in a TODGA-based system has never been reported ${ }^{11}$, but high extraction yields for $\mathrm{Bk}^{3+}$ could be expected based on the behavior of $\mathrm{Cf}^{3+}$. In nitric solutions without chelator, quantitative co-extraction of ${ }^{249} \mathrm{Bk}^{3+}$ and ${ }^{249} \mathrm{Cf}^{3+}$ by TODGA was observed, leading to no practical separation between the metals (Fig. 5). In stark contrast, addition of $343 \mathrm{HOPO}$ drastically changes the Bk extraction profile: less than $1 \% \mathrm{Bk}$ is extracted throughout the acidity range whereas $\mathrm{Cf}$ extraction remains undisturbed, due to the non-interaction between trivalent ions and the aqueous chelator at high acidity. The two adjacent actinides can be separated over a very broad acidity range (0.5-10 $\left.\mathrm{M} \mathrm{HNO}_{3}\right)$. Even if an unfavorable initial ratio $\mathrm{Cf} / \mathrm{Bk}$ was used in those experiments
(Cf/Bk 12,000), ${ }^{249} \mathrm{Bk}$ samples completely exempt of ${ }^{249} \mathrm{Cf}$ were obtained, notably so after only a single extraction. Experiments at various concentrations of extractant further confirmed the reliability of the TODGA- $\mathrm{HNO}_{3}-343 \mathrm{HOPO}$ separation formulation (Supplementary Fig. 9) with $\mathrm{SF}_{\mathrm{Cf} / \mathrm{Bk}}>1,000,000$, regardless of the TODGA and $\mathrm{HNO}_{3}$ concentrations. Additional separation experiments with $\mathrm{Gd}^{3+}$ and $\mathrm{Lu}^{3+}$ further evidenced the reliability of this system for purifying Bk (Supplementary Fig. 10). Finally, the separation method was tested at the $\mathrm{mCi}$ level. Legacy samples of ${ }^{249} \mathrm{Bk} /{ }^{249} \mathrm{Cf}$ used in previous studies ${ }^{44,47}$ were gathered, evaporated, incinerated and reconstituted in $3 \mathrm{M}$ $\mathrm{HNO}_{3}$ solutions containing multiple $\mathrm{mCi}$ of ${ }^{249} \mathrm{Bk}$ with a $\mathrm{Cf} / \mathrm{Bk}$ ratio of $\sim 3.4 \mathrm{~mol} / \mathrm{mol}$. The solution was split in five, $343 \mathrm{HOPO}$ was added, and an extraction step was performed using TODGA. As detailed in Table 1, after only a single step and regardless of 

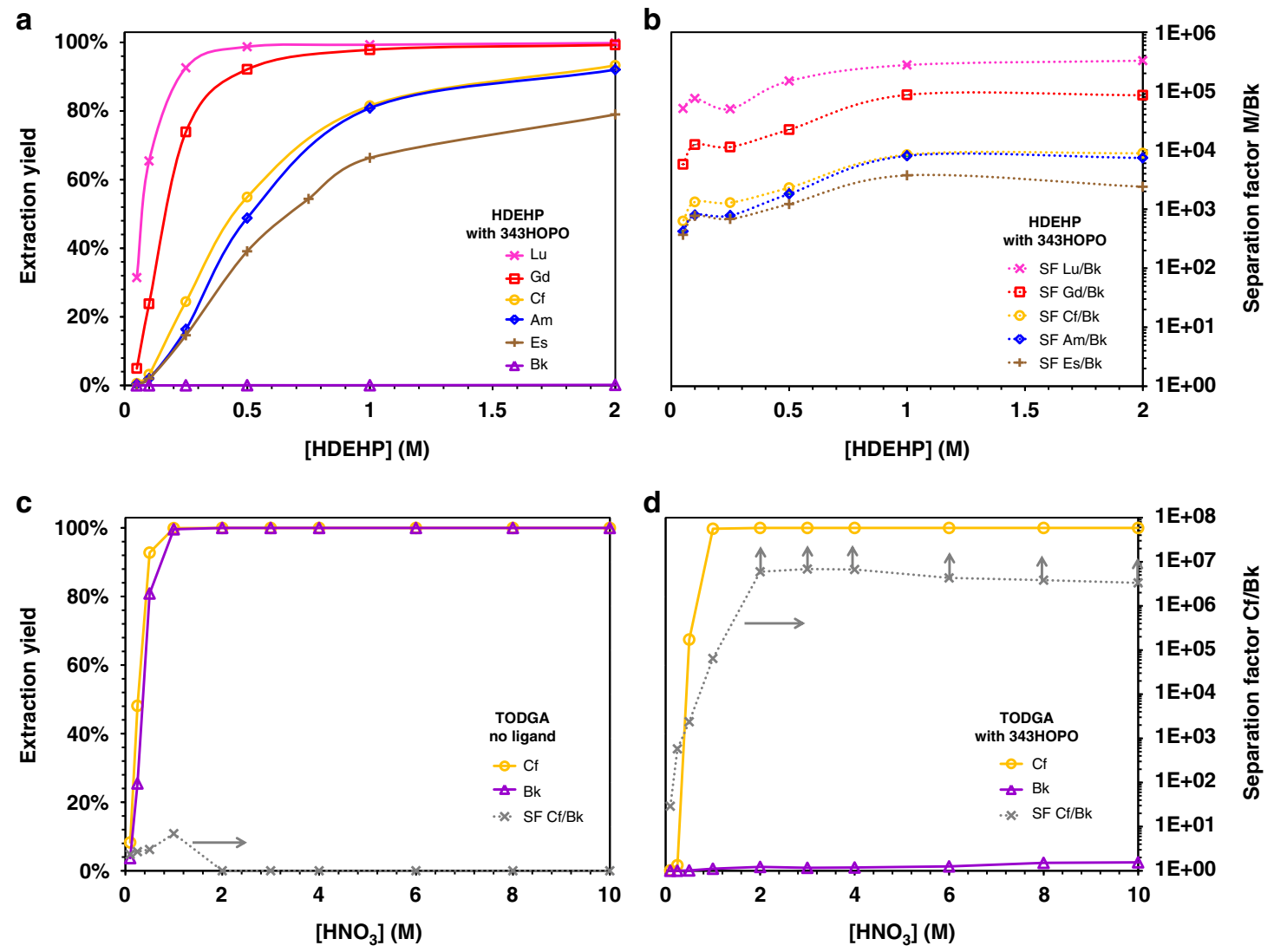

Fig. 5 Separation of Bk, from Gd, Lu, Am, Cf, and Es. a Extraction of ${ }^{177} \mathrm{Lu}$ (crosses), ${ }^{153} \mathrm{Gd}$ (squares), ${ }^{243} \mathrm{Am}$ (diamonds), ${ }^{249} \mathrm{Bk}$ (triangles), ${ }^{249} \mathrm{Cf}$ (circles)

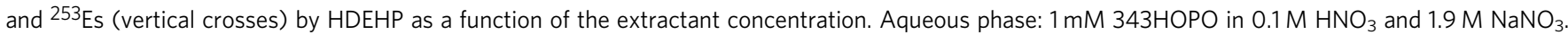
Organic phase: HDEHP in kerosene. $\mathbf{b}$ Corresponding separation factors. A log scale is used for clarity. See Supplementary Fig. 8 for results as a function of the phase ratio. $\mathbf{c}$ and $\mathbf{d}$ show the extraction yields of ${ }^{249} \mathrm{Bk}$ and ${ }^{249} \mathrm{Cf}$ by TODGA (solid lines) and separation factors $\mathrm{Cf} / \mathrm{Bk}$ (dotted lines) as a function of the acidity and in the absence or presence of $1 \mathrm{mM} 343 \mathrm{HOPO}$, respectively. Aqueous phase: 0 or $1 \mathrm{mM} 343 \mathrm{HOPO}$ in $\mathrm{HNO}_{3}$. Organic phase: $0.1 \mathrm{M}$ TODGA in kerosene. $T=25^{\circ} \mathrm{C} . \mathrm{O} / \mathrm{A}=1$, one contact. Points with arrows are lower limits

\section{Table 1 Separation of ${ }^{249} \mathrm{Bk}$ and ${ }^{249} \mathrm{Cf}$ at the $\mathrm{mCi}$ level using TODGA and 343HOPOa}

\begin{tabular}{|c|c|c|c|}
\hline Conditions & Phase & Radiopurity & Chemical purity \\
\hline \multirow{3}{*}{$\begin{array}{l}\mathrm{O} / \mathrm{A}=0.5 \\
{[343 \mathrm{HOPO}]=1 \mathrm{mM}}\end{array}$} & Initial & $\begin{array}{l}\text { Bk: } 99.13 \% \pm 0.13 \\
\text { Cf: } 0.87 \% \pm 0.03\end{array}$ & $\begin{array}{l}\text { Bk: } 22.63 \% \pm 0.54 \\
\text { Cf: } 77.37 \% \pm 0.54\end{array}$ \\
\hline & Organic & $\begin{array}{l}\text { Bk: } 52.70 \% \\
\text { Cf: } 47.30 \%\end{array}$ & Cf: $99.71 \%$ \\
\hline & Aqueous & Bk: > $99.999 \%$ & Bk: $>99.8 \%$ \\
\hline \multirow[t]{2}{*}{$\begin{array}{l}\mathrm{O} / \mathrm{A}=1.0 \\
{[343 \mathrm{HOPO}]=1 \mathrm{mM}}\end{array}$} & Organic & $\begin{array}{l}\text { Bk: } 64.85 \% \\
\text { Cf: } 35.15 \%\end{array}$ & Cf: $99.5 \%$ \\
\hline & Aqueous & Bk: > $99.999 \%$ & Bk: $>99.8 \%$ \\
\hline \multirow[t]{2}{*}{$\begin{array}{l}\mathrm{O} / \mathrm{A}=2.0 \\
{[343 \mathrm{HOPO}]=1 \mathrm{mM}}\end{array}$} & Organic & $\begin{array}{l}\text { Bk: } 70.60 \% \\
\text { Cf: } 29.40 \%\end{array}$ & Cf: $99.4 \%$ \\
\hline & Aqueous & Bk: > $99.999 \%$ & Bk: $>99.8 \%$ \\
\hline \multirow[t]{2}{*}{$\begin{array}{l}\mathrm{O} / \mathrm{A}=1.0 \\
{[343 \mathrm{HOPO}]=5 \mathrm{mM}}\end{array}$} & Organic & $\begin{array}{l}\text { Bk: } 79.72 \% \\
\text { Cf: } 20.28 \%\end{array}$ & Cf: $99.0 \%$ \\
\hline & Aqueous & Bk: >99.999 \% & Bk: $>99.8 \%$ \\
\hline \multirow[t]{2}{*}{$\begin{array}{l}\mathrm{O} / \mathrm{A}=1.0 \\
{[343 \mathrm{HOPO}]=25 \mathrm{mM}}\end{array}$} & Organic & $\begin{array}{l}\text { Bk: } 84.94 \% \\
\text { Cf: } 15.06 \%\end{array}$ & Cf: $98.6 \%$ \\
\hline & Aqueous & Bk: > $99.999 \%$ & Bk: $>99.8 \%$ \\
\hline
\end{tabular}

aseparation conditions: $0.1 \mathrm{M}$ TODGA in kerosene; $343 \mathrm{HOPO}$ in $3 \mathrm{M} \mathrm{HNO}_{3} . \mathrm{T}=25^{\circ} \mathrm{C}$. One contact. Activity level: $2 \mathrm{mCi} \mathrm{mL}^{-1}\left(74 \mathrm{GBq} \mathrm{L}^{-1}\right)$

the conditions used, very efficient separation was observed with the recovery of essentially pure ${ }^{249} \mathrm{Bk}$ in the aqueous phase (radiopurity $>99.999 \%$, chemical purity $>99.8 \%$ ) and high-purity ${ }^{249} \mathrm{Cf}$ in the organic phase (chemical purity $>99.5 \%$ ). These results further confirm the proposed strategy could be used with high-activity samples, and scaled up to either produce high-purity
$\mathrm{Bk}$ isotopes or to remove $\mathrm{Bk}$ traces during $\mathrm{Cm}$, $\mathrm{Cf}$, Es, or Fm production. Subsequent recovery of all isotopes would be facilitated by incineration and reconstitution in the desired matrix.

Noteworthy, the results presented above, although already providing better $\mathrm{Cf} / \mathrm{Bk}$ separation than with any published method, do not represent optimum system performance since 343 HOPO was not initially developed for separation applications and molecules with even higher selectivity could be designed. In addition, the three isotope purification examples examined in this work demonstrate the versatility of the proposed separation strategy, which could undoubtedly be transposed to other critical challenges ${ }^{1}$, such as those encountered with ${ }^{89} \mathrm{Zr}^{4+} / \mathrm{Y}^{3+},{ }^{177} \mathrm{Lu}^{3}$ ${ }^{+} / \mathrm{Hf}^{4+},{ }^{134} \mathrm{La}^{3+} /{ }^{134} \mathrm{Ce}^{4+}$, or ${ }^{117} \mathrm{~m} \mathrm{Sn}^{4+} /{ }^{116} \mathrm{Cd}^{2+}$ purifications. We anticipate that the use of HOPO ligand derivatives as aqueous chelating hold-back reagents could pave the way to more reliable, flexible and efficient methodologies for metal cation separations.

\section{Methods}

Caution. The following isotopes were used in this work: ${ }^{153} \mathrm{Gd}\left(\varepsilon, t_{1 / 2}=240\right.$ days, $130 \mathrm{TBq} / \mathrm{g}),{ }^{177} \mathrm{Lu}\left(\beta^{-}, t_{1 / 2}=6.6\right.$ days, $\left.4,100 \mathrm{TBq} / \mathrm{g}\right),{ }^{225} \mathrm{Ac}\left(\alpha, t_{1 / 2}=9.95\right.$ days, $2,100 \mathrm{TBq} / \mathrm{g}),{ }^{233} \mathrm{U}\left(\alpha, t_{1 / 2}=159200\right.$ years, $\left.0.36 \mathrm{GBq} / \mathrm{g}\right),{ }^{241} \mathrm{Pu}\left(\beta^{-}, t_{1 / 2}=14.3\right.$ years, $3.8 \mathrm{TBq} / \mathrm{g}),{ }^{242} \mathrm{Pu}\left(\alpha, t_{1 / 2}=3.74 \times 10^{5}\right.$ years, $\left.0.15 \mathrm{GBq} / \mathrm{g}\right),{ }^{243} \mathrm{Am}\left(\alpha, t_{1 / 2}=7388\right.$ year, $7.4 \mathrm{GBq} / \mathrm{g}),{ }^{249} \mathrm{Bk}\left(\beta^{-}, t_{1 / 2}=0.9\right.$ year, $\left.61 \mathrm{TBq} / \mathrm{g}\right),{ }^{249} \mathrm{Cf}\left(\alpha, t_{1 / 2}=352\right.$ year, $0.15 \mathrm{TBq} /$ $\mathrm{g})$, and ${ }^{253} \mathrm{Es}\left(\alpha, t_{1 / 2}=20.5\right.$ days, $\left.932 \mathrm{TBq} / \mathrm{g}\right)$. All are highly radioactive, presenting serious health risks, and were manipulated in facilities specially designed for safe handling of long-lived radioactive materials at the Lawrence Berkeley National Laboratory (LBNL). 
Materials. ${ }^{153} \mathrm{Gd}(\mathrm{III})$ chloride and ${ }^{233} \mathrm{U}$ (VI) nitrate were purchased from Eckert \& Ziegler Isotope Products (Valencia, CA). ${ }^{177} \mathrm{Lu}(\mathrm{III})$ chloride was purchased from Perkin Elmer Health Sciences (Shelton, CT). A Pu(IV) chloride stock solution containing a $50 / 50$ mixture $(\mathrm{Bq} / \mathrm{Bq})$ of ${ }^{241} \mathrm{Pu}$ and ${ }^{242} \mathrm{Pu}$ and a stock solution of ${ }^{243} \mathrm{Am}$ (III), prepared by dissolution of ${ }^{243} \mathrm{Am}_{2} \mathrm{O}_{3}$ in $1 \mathrm{M} \mathrm{HNO}_{3}$, were from LBNL inventory. ${ }^{225} \mathrm{Ac}(\mathrm{III}),{ }^{249} \mathrm{Bk}(\mathrm{III})$, and ${ }^{249} \mathrm{Cf}(\mathrm{III})$ were obtained as chlorides from ORNL. A ${ }^{253} \mathrm{Es}$ (III) perchlorate solid sample was provided by Prof. J. Shafer (Colorado School of Mines). $343 \mathrm{HOPO}$ was from LBNL inventory ${ }^{14}$. Standard solutions of $0.1 \mathrm{M}$ and $6.0 \mathrm{M} \mathrm{HNO}_{3}$ (BDH VWR Analytical), $70 \% \mathrm{HNO}_{3}$ (Sigma Aldrich), $\mathrm{NaNO}_{3}(>99 \%$, ACS grade, VWR), sodium lactate (Sigma Aldrich), TODGA ( $>99 \%$, Technocomm Ltd.), HDEHP ( $>95 \%$, Merck), tributyl phosphate (TBP, $>98 \%$, Alpha Aesar), kerosene low odor (Alpha Aesar), DTPA (>98\%, TCI), and Ultima Gold LLT (Perkin Elmer) were used as received. All solutions were prepared using deionized water purified by a Millipore Milli-Q reverse osmosis cartridge system. Stocks were stored at $8^{\circ} \mathrm{C}$ in the dark between experiments.

Methods. $\mathrm{pH}$ measurements were performed with a glass electrode (Metrohm Micro Combi - response to $\left[\mathrm{H}^{+}\right]$) calibrated at $25.0^{\circ} \mathrm{C}$ using three NIST standards. Extraction samples were analyzed by liquid scintillation counting (LSC). The distribution coefficient, $D(\mathrm{M})$, of a given metal, $\mathrm{M}$, is defined in Eq. (1), where $[\mathrm{M}]_{\text {organic }}$ and $[\mathrm{M}]_{\text {aqueous }}$ are the respective total concentrations of $\mathrm{M}$ in the organic and aqueous layers, after extraction. Both concentrations are proportional to the volumetric activity (in $\mathrm{Bq} \mathrm{L}^{-1}$ ) determined by LSC. The separation factor, $\mathrm{SF}_{\mathrm{M} 1 / \mathrm{M} 2}$, between two metals, $\mathrm{M}_{1}$ and $\mathrm{M}_{2}$, and extraction yield were calculated according to Eq. (2) and Eq. (3), respectively.

$$
\begin{gathered}
D(\mathrm{M})=\frac{[\mathrm{M}]_{\text {organic }}}{[\mathrm{M}]_{\text {aqueous }}}=\frac{[\text { Activity }]_{\text {organic }}}{[\text { Activity }]_{\text {aqueous }}} \\
\mathrm{SF}_{\mathrm{M} 1 / \mathrm{M} 2}=\frac{D\left(\mathrm{M}_{1}\right)}{D\left(\mathrm{M}_{2}\right)} \\
\text { \%Extraction }=\frac{[\text { Activity }]_{\text {organic }} \times V_{\text {organic }}}{[\text { Activity }]_{\text {organic }} \times V_{\text {organic }}+[\text { Activity }]_{\text {aqueous }} \times V_{\text {aqueous }}} \times 100
\end{gathered}
$$

In a typical experiment, the solvent (extractant diluted in kerosene) was preconditioned by shaking one volume of solvent with three volumes of aqueous phase (typically $\mathrm{HNO}_{3}$ ) at room temperature for $1 \mathrm{~h}$, thrice. For radioisotope extractions, at least $400 \mu \mathrm{L}$ aqueous phase (typically containing $\mathrm{HNO}_{3}$, a chelator and a radioisotope) and solvent were placed in air-tight screw-capped plastic tubes, triply-contained, and shaken in a thermoshaker at $300 \mathrm{rpm}, 25^{\circ} \mathrm{C}$, for at least $30 \mathrm{~min}$. Samples were then centrifuged for $5 \mathrm{~min}$ at $3000 \mathrm{rpm}$ and phases separated before analysis. LSC analyses were performed on a Packard Tri-Carb B4430 instrument (Perkin Elmer) after mixing sample aliquots or sample dilution aliquots $(10-200 \mu \mathrm{L})$ with $10 \mathrm{~mL}$ of scintillation cocktail (UltimaGold LLT). Samples were counted for at least $6 \mathrm{~min}$ and results were background subtracted. The analytical samples contained between 0 and 800,000 CPM. Mixtures of ${ }^{249} \mathrm{Bk}$ and ${ }^{249} \mathrm{Cf}$ were analyzed using $\alpha / \beta$ discrimination and energy windows were set to $0-50 \mathrm{keV}$ for low-energy $\beta$ particles of ${ }^{249} \mathrm{Bk}$ and $50-1000 \mathrm{keV}$ for $\alpha$ particles of ${ }^{249} \mathrm{Cf} .{ }^{243} \mathrm{Am}$ and ${ }^{225} \mathrm{Ac}$ samples were counted at secular equilibrium.

\section{Data availability}

All data generated or analysed during this study are included in this published article (and its supplementary information files).

Received: 4 March 2019 Accepted: 25 April 2019

Published online: 04 June 2019

\section{References}

1. NSAC Isotopes Subcommittee. Meeting isotope needs and capturing opportunities for the future: the 2015 long range plan for the DOE-NP isotope program. 1-160 (US DOE and NSF Nuclear Science Advisory Committee, Argonne, IL, USA, 2015).

2. Hagemann, U. B. et al. In vitro and in vivo efficacy of a novel CD33-targeted thorium-227 conjugate for the treatment of acute myeloid leukemia. Mol. Cancer Ther. 15, 2422-2431 (2016).

3. Witze, A. Nuclear power: desperately seeking plutonium. Nat. News $\mathbf{5 1 5}$, 484-486 (2014).

4. Veliscek-Carolan, J. Separation of actinides from spent nuclear fuel: a review. J. Hazard. Mater. 318, 266-281 (2016).

5. Roberto, J. B. et al. Actinide targets for the synthesis of super-heavy elements. Nucl. Phys. A 944, 99-116 (2015).
6. Oganessian, Y. T. et al. Experimental studies of the ${ }^{249} \mathrm{Bk}+{ }^{48} \mathrm{Ca}$ reaction including decay properties and excitation function for isotopes of element 117 , and discovery of the new isotope ${ }^{277}$ Mt. Phys. Rev. C. 87, 054621 (2013).

7. Wang, Y. et al. Facile and efficient decontamination of thorium from rare earths based on selective selenite crystallization. Inorg. Chem. 57, 1880-1887 (2018).

8. Yin, X. et al. Rare earth separations by selective borate crystallization. Nat. Comm. 8, 14438 (2017).

9. Beltrami, D. et al. Recovery of uranium from wet phosphoric acid by solvent extraction processes. Chem. Rev. 114, 12002-12023 (2014).

10. Leydier, A. et al. Recovery of uranium (VI) from concentrated phosphoric acid using bifunctional reagents. Hydrometallurgy 171, 262-266 (2017).

11. Zhu, Z.-X., Sasaki, Y., Suzuki, H., Suzuki, S. \& Kimura, T. Cumulative study on solvent extraction of elements by $\mathrm{N}, \mathrm{N}, \mathrm{N}^{\prime}, \mathrm{N}^{\prime}$-tetraoctyl-3oxapentanediamide (TODGA) from nitric acid into n-dodecane. Anal. Chim. Acta 527, 163-168 (2004).

12. Horwitz, E. P. \& Bloomquist, C. A. A. Chemical separations for super-heavy element searches in irradiated uranium targets. J. Inorg. Nucl. Chem. 37, 425-434 (1975).

13. Cary, S. K. et al. Advancing understanding of the +4 Metal Extractant Thenoyltrifluoroacetonate (TTA ${ }^{-}$); Synthesis and Structure of $\mathrm{M}^{\mathrm{IV}} \mathrm{TTA}_{4}$ $\left(\mathrm{M}^{\mathrm{IV}}=\mathrm{Zr}, \mathrm{Hf}, \mathrm{Ce}, \mathrm{Th}, \mathrm{U}, \mathrm{Np}, \mathrm{Pu}\right)$ and $\mathrm{M}^{\mathrm{III}}(\mathrm{TTA})_{4}{ }^{-}\left(\mathrm{M}^{\mathrm{III}}=\mathrm{Ce}, \mathrm{Nd}, \mathrm{Sm}, \mathrm{Yb}\right)$. Inorg. Chem. 57, 3782-3797 (2018).

14. Abergel, R. J. et al. Biomimetic actinide chelators: an update on the preclinical development of the orally active hydroxypyridonate decorporation agents 3,4,3-LI(1,2-HOPO) and 5-LIO(Me-3,2-HOPO). Health Phys. 99, 401-407 (2010).

15. Gorden, A. E. V., Xu, J., Raymond, K. N. \& Durbin, P. Rational design of sequestering agents for plutonium and other actinides. Chem. Rev. 103, 4207-4282 (2003).

16. Deri, M. A. et al. p-SCN-Bn-HOPO: a superior bifunctional chelator for ${ }^{89} \mathrm{Zr}$ ImmunoPET. Bioconjugate Chem. 26, 2579-2591 (2015).

17. Captain, I. et al. Engineered recognition of tetravalent zirconium and thorium by chelator-protein systems: toward flexible radiotherapy and imaging platforms. Inorg. Chem. 55, 11930-11936 (2016).

18. Xu, J., Radkov, E., Ziegler, M. \& Raymond, K. N. Plutonium(IV) sequestration: structural and thermodynamic evaluation of the extraordinarily stable cerium(IV) hydroxypyridinonate complexes 1 . Inorg. Chem. 39, 4156-4164 (2000).

19. Deblonde, G. J.-P. et al. Solution thermodynamics and kinetics of metal complexation with a hydroxypyridinone chelator designed for thorium-227 targeted alpha therapy. Inorg. Chem. https://doi.org/10.1021/acs. inorgchem.8b02430 (2018).

20. Pham, T. A. et al. A macrocyclic chelator that selectively binds $\mathrm{Ln}^{4+}$ over $\mathrm{Ln}^{3}$ + by a factor of 1029. Inorg. Chem. 55, 9989-10002 (2016).

21. D'Aléo, A., Moore, E. G., Xu, J., Daumann, L. J. \& Raymond, K. N. Optimization of the sensitization process and stability of octadentate Eu(III) 1,2-HOPO complexes. Inorg. Chem. 54, 6807-6820 (2015).

22. $\mathrm{Xu}$, J. et al. Synthesis and initial evaluation for in vivo chelation of $\mathrm{Pu}(\mathrm{IV})$ of a mixed octadentate spermine-based ligand containing 4-Carbamoyl-3hydroxy-1-methyl-2(1H)-pyridinone and 6-Carbamoyl-1-hydroxy-2(1H)pyridinone. J. Med. Chem. 45, 3963-3971 (2002).

23. Allott, L. et al. Evaluation of DFO-HOPO as an octadentate chelator for zirconium-89. Chem. Comm. 53, 8529-8532 (2017).

24. Deblonde, G. J.-P., Lohrey, T. D., An, D. D. \& Abergel, R. J. Toxic heavy metal - $\mathrm{Pb}, \mathrm{Cd}, \mathrm{Sn}$ - complexation by the octadentate hydroxypyridinonate ligand archetype 3,4,3-LI(1,2-HOPO). New J. Chem. 42, 7649-7658 (2018).

25. Sturzbecher-Hoehne, M. et al. 3,4,3-LI(1,2-HOPO): In vitro formation of highly stable lanthanide complexes translates into efficacious in vivo europium decorporation. Dalton Trans. 40, 8340 (2011).

26. Sturzbecher-Hoehne, M., Deblonde, G. J.-P. \& Abergel, R. J. Solution thermodynamic evaluation of hydroxypyridinonate chelators 3,4,3-LI(1,2$\mathrm{HOPO}$ ) and 5- $\mathrm{LIO}(\mathrm{Me}-3,2-\mathrm{HOPO})$ for $\mathrm{UO}_{2}(\mathrm{VI})$ and $\mathrm{Th}(\mathrm{IV})$ decorporation. Radiochim. Acta 101, 359-366 (2013).

27. Wilson, J. J. et al. Evaluation of nitrogen-rich macrocyclic ligands for the chelation of therapeutic bismuth radioisotopes. Nucl. Med. Biol. 42, 428-438 (2015).

28. Ferrier, M. G. et al. Synthesis and characterization of the actinium aquo ion. ACS Cent. Sci. 3, 176-185 (2017).

29. Lundberg, D. \& Persson, I. The size of actinoid(III) ions - structural analysis vs. common misinterpretations. Coord. Chem. Rev. 318, 131-134 (2016).

30. Radchenko, V. et al. Application of ion exchange and extraction chromatography to the separation of actinium from proton-irradiated thorium metal for analytical purposes. J. Chromat. A 1380, 55-63 (2015).

31. Nash, K. L. The chemistry of TALSPEAK: a review of the science. Solv. Extract. Ion. Exch. 33, 1-55 (2015).

32. Braley, J. C., Grimes, T. S. \& Nash, K. L. Alternatives to HDEHP and DTPA for simplified TALSPEAK separations. Ind. Eng. Chem. Res. 51, 629-638 (2012). 
33. Glaser, A. \& Mian, Z. Fissile material stocks and production, 2008. Bull. At. Sci. 65, 35-47 (2009).

34. Zhao, P. et al. Plutonium(IV) and (V) sorption to goethite at sub-femtomolar to micromolar concentrations: redox transformations and surface precipitation. Environ. Sci. Technol. 50, 6948-6956 (2016).

35. Albright, D. \& Kramer, K. Stockpiles still growing. Bull. At. Sci. 60, 14-16 (2004).

36. Herbst, R. S., Baron, P. \& Nilsson, M. Standard and advanced separation: PUREX processes for nuclear fuel reprocessing. in Advanced Separation Techniques for Nuclear Fuel Reprocessing and Radioactive Waste Treatment (eds Nash, K. L. \& Lumetta, G. J.) 141-175 (Woodhead Publishing, Cambridge, UK, 2011).

37. Paviet-Hartmann, P., Riddle, C., Campbell, K. \& Mausolf, E. Overview of reductants utilized in nuclear fuel reprocessing/recycling. in Idaho National Laboratory Report INL/CON-12-28006. 79-86 (Idaho Falls, ID, USA, 2013).

38. Whittaker, D. et al. Applications of diglycolamide based solvent extraction processes in spent nuclear fuel reprocessing, part 1: TODGA. Solv. Extract. Ion. Exch. 36, 223-256 (2018).

39. Modolo, G., Asp, H., Schreinemachers, C. \& Vijgen, H. Recovery of actinides and lanthanides from high-level liquid waste by extraction chromatography using TODGA + TBP impregnated resins. Radiochimica. Acta. 95, 391-397 (2007).

40. Carrott, M. et al. Distribution of plutonium, americium and interfering fission products between nitric acid and a mixed organic phase of TODGA and DMDOHEMA in kerosene, and implications for the design of the 'EUROGANEX' process. Hydrometallurgy 152, 139-148 (2015).

41. Modolo, G., Asp, H., Schreinemachers, C. \& Vijgen, H. Development of a TODGA based process for partitioning of actinides from a PUREX raffinate part I: batch extraction optimization studies and stability tests. ESolv. Extract. Exch. 25, 703-721 (2007).

42. Öhrström, L. \& Reedijk, J. Names and symbols of the elements with atomic numbers 113, 115, 117 and 118 (IUPAC Recommendations 2016). Pure Appl. Chem. 88, 1225-1229 (2016).

43. Oganessian, Y. T. et al. Results from the First ${ }^{249} \mathrm{Cf}+{ }^{48} \mathrm{Ca}$ Experiment. in Lawrence Livermore National Laboratory Report 02/0302003. 11 (Livermore, CA, USA, 2017).

44. Deblonde, G. J.-P. et al. Spectroscopic and computational characterization of diethylenetriaminepentaacetic acid/transplutonium chelates: evidencing heterogeneity in the heavy actinide(III) series. Angew. Chem. Int. Ed. 57, 4521-4526 (2018).

45. Du, M., Tan, R. \& Boll, R. Applications of MP-1 anion exchange resin and Eichrom LN resin in berkelium-249 purification. J. Radio. Nucl. Chem. 318 619-629 (2018).

46. Deblonde, G. J.-P. et al. Chelation and stabilization of berkelium in oxidation state + IV. Nat. Chem. 9, 843-849 (2017).

47. Kelley, M. P. et al. Bond covalency and oxidation state of actinide ions complexed with therapeutic chelating agent 3,4,3-LI(1,2-HOPO). Inorg. Chem. 57, 5352-5363 (2018).

48. Deblonde, G. J.-P., Sturzbecher-Hoehne, M. \& Abergel, R. J. Solution thermodynamic stability of complexes formed with the octadentate hydroxypyridinonate ligand 3,4,3-LI(1,2-HOPO): a critical feature for efficient chelation of Lanthanide(IV) and Actinide(IV) ions. Inorg. Chem. 52, 8805-8811 (2013).

49. Sturzbecher-Hoehne, M., Kullgren, B., Jarvis, E. E., An, D. D. \& Abergel, R. J. Highly luminescent and stable hydroxypyridinonate complexes: a step towards new curium decontamination strategies. Chem. Eur. J. 20, 9962-9968 (2014).
50. Sturzbecher-Hoehne, M., Yang, P., D’Aléo, A. \& Abergel, R. J. Intramolecular sensitization of americium luminescence in solution: shining light on shortlived forbidden $5 f$ transitions. Dalton Trans. 45, 9912-9919 (2016).

\section{Acknowledgements}

This work was supported by the U.S. Department of Energy, Office of Science, Office of Basic Energy Sciences, Chemical Sciences, Geosciences, and Biosciences Division at LBNL under Contract DE-AC02-05CH11231. The Radiochemical Engineering and Development Center at ORNL is supported by the U.S. Department of Energy, Isotope Development and Production for Research and Applications Program. We thank Dr. Wayne Lukens Jr. (LBNL) for preparation of the Pu starting material, and Prof. Jenifer Shafer (Colorado School of Mines) for providing the Es starting material.

\section{Author contributions}

G.J-P.D. and R.J.A. designed the research. G-J.P.D. and A.R. collected experimental data. All of the authors discussed the results and commented on the manuscript.

\section{Additional information}

Supplementary Information accompanies this paper at https://doi.org/10.1038/s41467019-10240-x.

Competing interests: R.J.A. and G-J.P.D. are listed as inventors on patent applications filed by LBNL and describing inventions related to the research results presented here. The remaining authors declare no competing interests.

Reprints and permission information is available online at http://npg.nature.com/ reprintsandpermissions/

Journal peer review information: Nature Communications thanks Thomas AlbrechtSchmitt and the other, anonymous, reviewer(s) for their contribution to the peer review of this work.

Publisher's note: Springer Nature remains neutral with regard to jurisdictional claims in published maps and institutional affiliations.

pen Access This article is licensed under a Creative Commons Attribution 4.0 International License, which permits use, sharing, adaptation, distribution and reproduction in any medium or format, as long as you give appropriate credit to the original author(s) and the source, provide a link to the Creative Commons license, and indicate if changes were made. The images or other third party material in this article are included in the article's Creative Commons license, unless indicated otherwise in a credit line to the material. If material is not included in the article's Creative Commons license and your intended use is not permitted by statutory regulation or exceeds the permitted use, you will need to obtain permission directly from the copyright holder. To view a copy of this license, visit http://creativecommons.org/ licenses/by/4.0/.

This is a U.S. government work and not under copyright protection in the U.S.; foreign copyright protection may apply 2019 